Egyptian

Orthodontic Journal

\title{
MINISCREWS SUPPORTED MAXILLARY EN-MASSE RETRACTION WITH AND WITHOUT PALATAL CORTICOTOMY
}

\author{
Walaa E. El.Gemeay ${ }^{1}$, Mohamed A. Nadim², \\ Tamer Abd El Bari Hamed ${ }^{3}$, Tamer M. Bedair ${ }^{4}$, Abbadi A.EL-Kadi ${ }^{5}$ \\ ABSTRACT:
}

The purpose of this study was to evaluate miniscrew supported maxillary en masse retraction with and without corticotomy-facilitated orthodontics. Twenty patients with maxillary or bimaxillary protrusion requiring orthodontic treatment with upper anterior en masse retraction in the extraction space of first premolars were selected. Patients were divided into two groups; control and corticotomy group each group consisted of 10 subjects. The retraction time was estimated. The cephalometric radiographs were analyzed for differences between pre-treatment and post-treatment variables that included skeletal and dental relationships. There was a significant difference in retraction time between control and corticotomy groups $(p<0.001)$. Radiographic evaluation showed significant maxillary incisor retraction. Cortictomy assisted orthodontics reduces the duration of treatment compared to that without corticotomy.

1- Assistant Lecturer, Department of Orthodontics, Faculty of Dentistry, Suez Canal University.

2- Assistant Professor, Department of Orthodontics, Faculty of Dentistry, Suez Canal University.

3-Assistant Professor, Department of Oral and Maxillofacial Surgery, Faculty of Dentistry, Suez Canal University.

4-Lecturer of Orthodontics, Department of orthodontics, Faculty of Dentistry, Suez Canal University.

5- Professor, Department of Orthodontics, Faculty of Dentistry, Suez Canal University. 
Egyptian

Orthodontic Journal

\section{INTRODUCTION}

Time is an essential factor in the course of orthodontic treatment. Alveolar corticotomies have been used for several years to shorten the time of orthodontic tooth movement. Corticotomy is a procedure where only the cortical bone is cut, perforated, or mechanically altered in a controlled surgical manner.

En-masse retraction of the six anterior teeth, instead of step-by-step retraction of the canine and four incisors can reduce treatment time. The use of miniscrews in the mechanics of en masse retraction also can reduce the treatment time effectively.

kole ${ }^{1}$ reported combining orthodontics with corticotomy surgery and completed the active tooth movement in adult orthodontic cases in 6-12 weeks. This faster tooth movement was believed to be due to the reduced resistance of the cortical bone by surgical procedure. Wilcko et al ${ }^{2,3,4}$ further modified the corticotomy-assisted orthodontic technique with the addition of alveolar augmentation. They demonstrated through a surface computed tomographic (CT) scan evaluation that corticotomies could increase tooth movement by increasing bone turnover and decreasing bone density.

Germec et $\mathrm{al}^{5}$ reported what they called a "modified corticotomy," where they demonstrated a "conservative" technique, to shorten the treatment time during lower incisor retraction. Nowzari et $\mathrm{al}^{6}$ used an autogenous bone graft in conjunction with corticotomies to treat a 41-year-old man with a Class II division 2 crowded occlusion in 8 months.. Aljhani and Aldrees ${ }^{7}$ completed treatment of a 22 -year-old woman who presented with an anterior open bite and flared/spaced maxillary and mandibular incisors in 5 months.

Fischer ${ }^{8}$ compared the movement of impacted canines after surgical exposure using conventional surgical technique with their contralateral canines exposed using a corticotomy assisted technique, and he concluded that corticotomy assisted surgical technique reduced the orthodontic treatment time by $28-33 \%$. Mostafa et $\mathrm{al}^{9}$ concluded that a restricted corticotomy of the maxillary anterior alveolar segment was successful in the treatment of subjects with anterior open bites rapidly. 
Maximum anchorage is commonly required in patients with severe protrusion. Lai et $\mathrm{al}^{10}$, Park et al ${ }^{11}$, Upadhyay et al ${ }^{12}$ and Yao et al ${ }^{13}$ concluded that mini-implants provided absolute anchorage to allow greater skeletal, dental, and esthetic changes in patients requiring maximum anterior retraction, when compared with other conventional methods of space closure. Iino et al ${ }^{14}$ reported shortening of orthodontic, when orthodontic treatment combined with corticotomy and the placement of titanium miniplates were performed in an adult patient with flaring of the maxillary and mandibular incisors.

There are many case reports that have been published in the literature regarding the corticotomy procedure and its advantages. Several studies have described orthodontic miniscrews for rigid anchorage. However, studies of treatment results using miniscrew combined with corticotomy are limited. Therefore, the purpose of the present study was to evaluate the effect of treatment and duration of retraction time when corticotomy used for en-masse retraction by using miniscrew as anchorage and compared with that without corticotomy.

\section{MATERIALS AND METHODS}

\section{The sample:}

This study was composed of twenty female adult patients ranging in age from 18 to 27 years. They were selected with maxillary or bimaxillary protrusion from patients seeking orthodontic treatment at the Orthodontic Department, Faculty of Dentistry, Suez Canal University Patients were divided into control and corticotomy groups:

\section{Group 1 (G1) subjects:}

10 patients treated with mini screw dependent en masse retraction.

\section{Group 2 (G2) subjects:}

10 patients treated with mini screw dependent en masse retraction associated with palatal corticotomy facilitated technique

The patients were informed of the surgical procedure and signed an informed consent before the initiation of treatment

\section{Records:}

The following records were taken for all the patients before and after treatment: 
- Digital panoramic radiograph.

- Digital lateral cephalometric radiograph.

- Photographs, both extra-oral and intra-oral photographs

- Time taken for complete space closure recorded and compared between the two groups

After placement of maxillary and mandibular fixed appliances and completion of the levelling and alignment phase of treatment, miniscrew implants (AbsoAnchor, Dentos, Daegu, Korea; diameter, $1.3 \mathrm{~mm}$; length, $8 \mathrm{~mm}$ ), used as skeletal anchor units, were placed bilaterally between the maxillary second premolar and the first molar (figure 1). When $0.018 \times 0.025$ inch. St.St maxillary arch wire was inserted, crimpable hooks were placed distal to the lateral incisor

The patients of group (G1) were referred to the department of oral surgery for extraction of the upper first premolars. The patients in the corticotomy group ( $\mathrm{G} 2$ ) were referred for extraction and corticotomy procedure.

\section{Surgical procedure:}

The surgical procedure was performed under local anesthesia. A full thickness mucoperiosteal flaps were reflected palatally around all the upper anterior teeth from the distal surface of the upper right first premolar to the distal surface of the upper left first premolar.Following the reflection of full thickness flaps, circumscribing corticotomy cuts were performed. Vertical cuts in the cortical bone were made about 1-2 $\mathrm{mm}$ below the alveolar crest between the roots of teeth and were extended 2-3 $\mathrm{mm}$ beyond the apices of the anterior teeth (figure 2).

Vertical corticotomy cuts were connected beyond the apices of teeth with scalloped horizontal corticotomy cuts. The corticotomy cuts was performed with a small fissure surgical bur in a high speed handpiece under water cooling. Bio-Gen cortical granules (Bioteck S.p.A., Via E. Fermi 49, 36057 Arcugnano (Vicenza), Italy) as bone graft material were mixed with saline and placed over areas that have undergone corticotomies (figure 3). 
After the completion of surgery, sutures were given after placing the raised flap back. All the patients were given post-operative antibiotics and anti-inflammatory agents 5 days following the surgery.To maximize the effects of corticotomy for orthodontic tooth movement, active orthodontic en masse retraction of the 6 maxillary anterior teeth was initiated within one week after the corticotomy procedure. Power chains were used to close the extraction spaces and en masse retraction of the six maxillary anterior teeth from the mini screw to the crimpable hook on the arch wire. Power chains were replaced every 3 weeks in G1 and were replaced every 2 weeks for G2.

Time taken for complete space closure was recorded from the day of application of the en masse retraction force to end of the space closure. Lateral cephalograms at pretreatment (T1) and after treatment (T2) were used for cephalometric analysis.
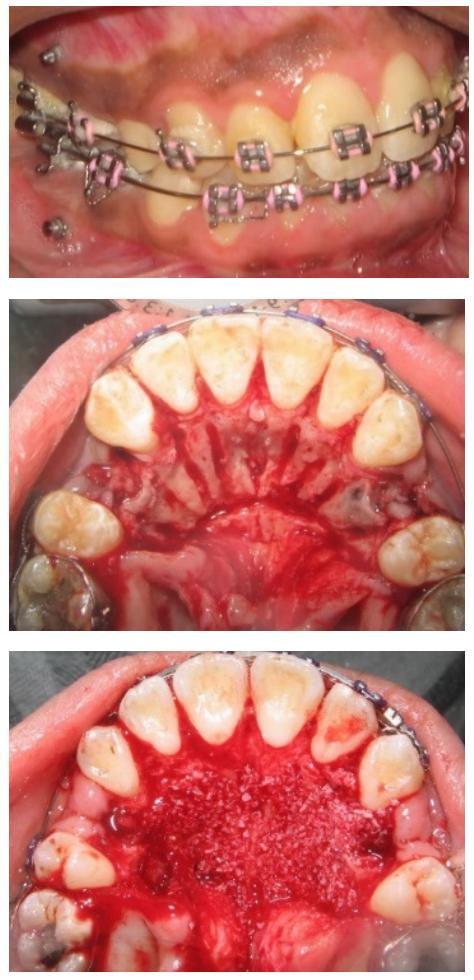

Figure 1: Mini-screw after placement

Figure (2): Interradicular corticotomy cuts

Figure (3): Bone graft placement 


\section{Egyptian}

Orthodontic Journal
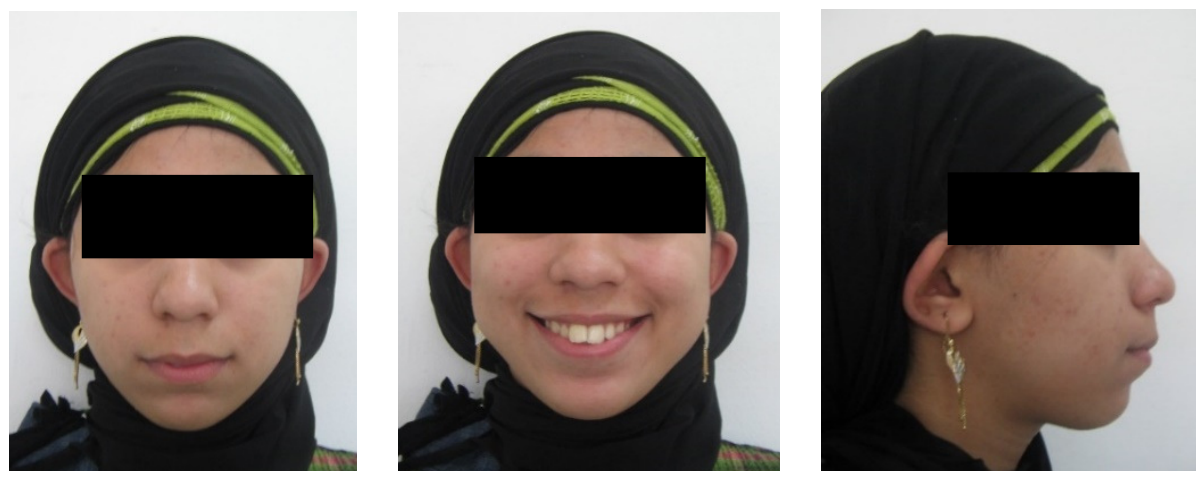

figure (4): Pre-treatment extraoral photograph for a patient selected from Group 1
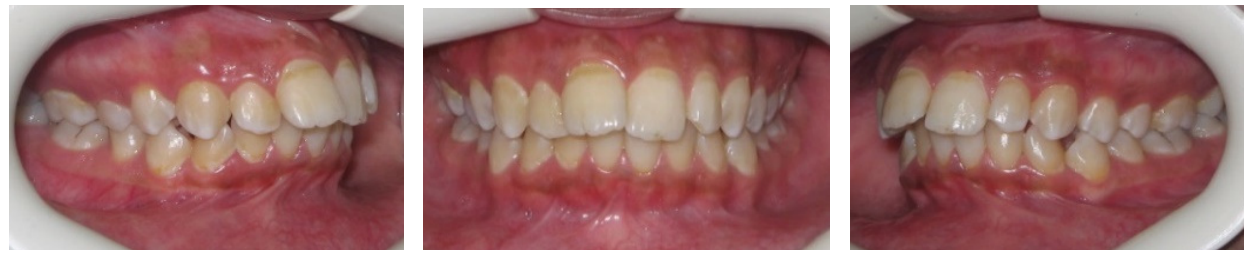

Figure (5): Pre-treatment intraoral photograph for a patient selected from Group 1
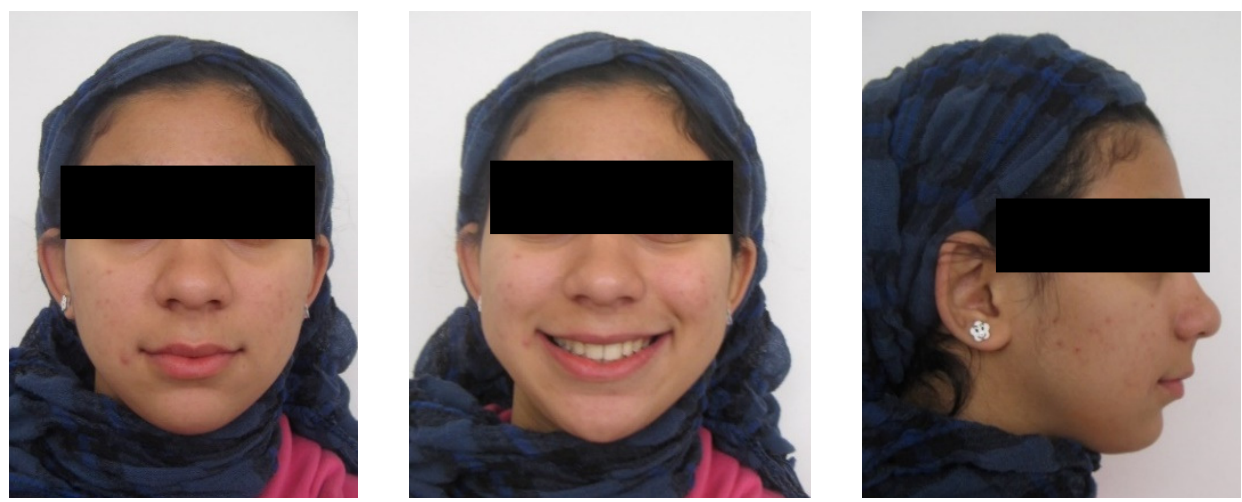

Figure (6): Post-treatment extraoral photograph for a patient selected from Group 1

Volume 47 - June 2015 


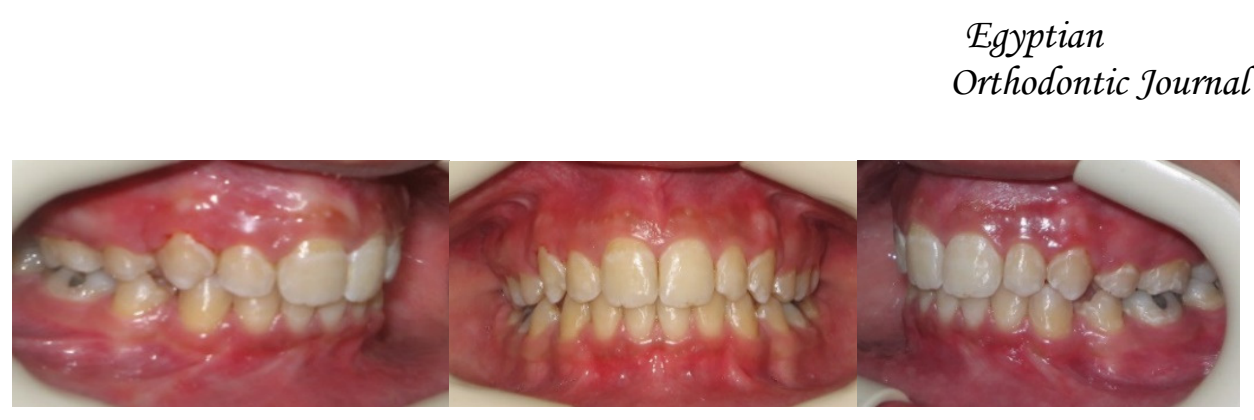

Figure (7): Post-treatment intraoral photograph for a patient selected from Group 1
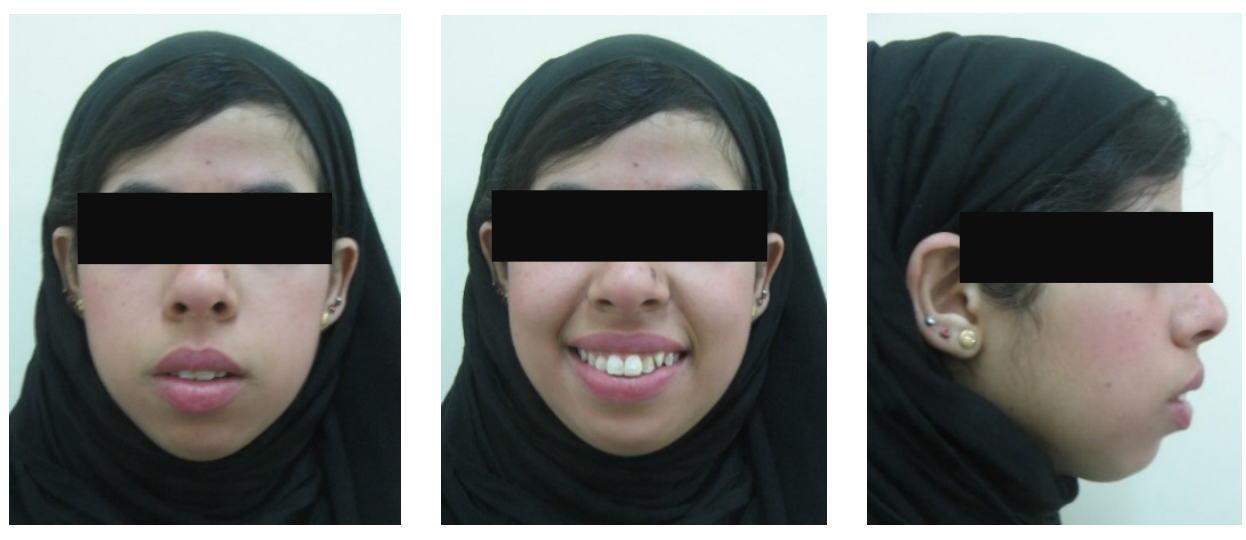

figure(8): pre-treatment extraoral photograph for a patient selected from Group 2

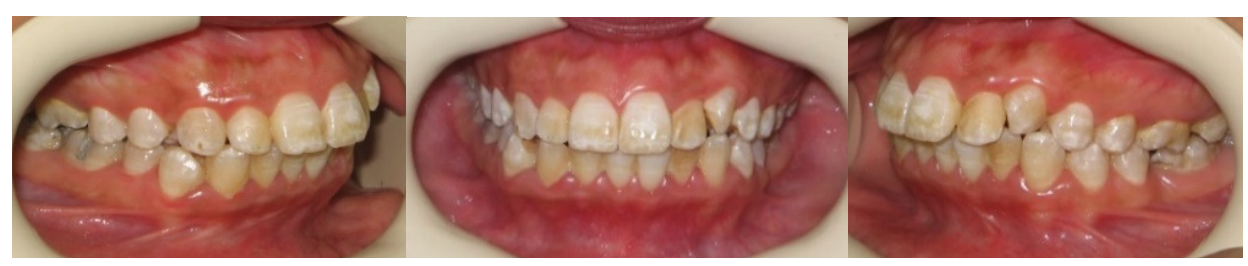

figure(9): Pre-treatment intraoral photograph for a patient selected from Group 2 

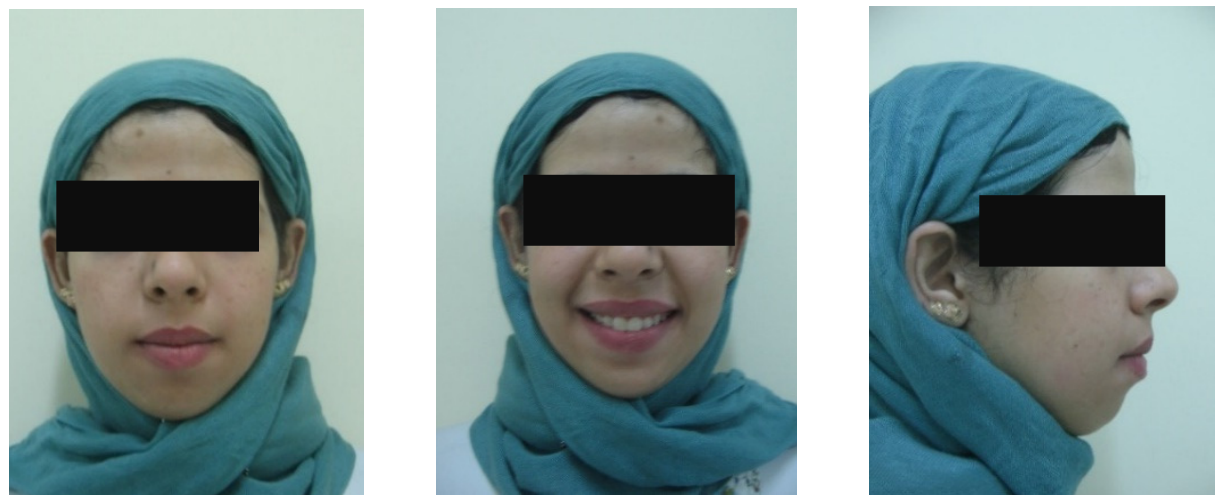

Figure (10): Post-treatment extraoral photograph for a patient selected from Group 2
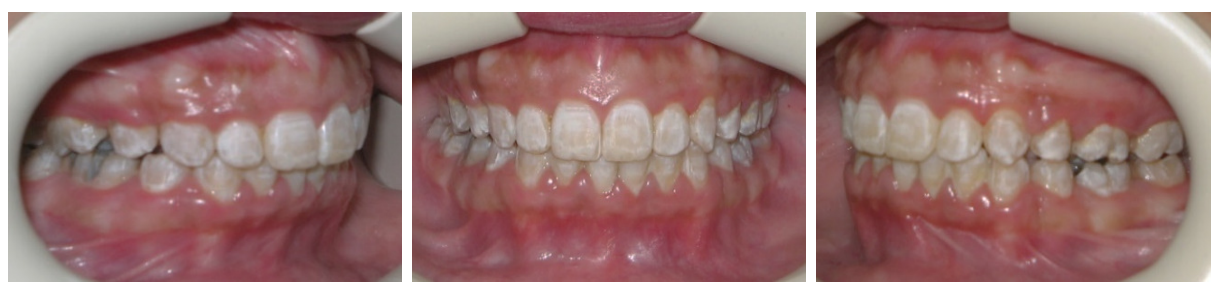

Figure(11): Post-treatment intraoral photograph for a patient selected from Group 2

\section{STATISTICAL ANALYSIS}

Statistical analysis was carried out using SPSS program (SPSS, 2008). The mean and standard deviation for the variables were calculated. Pre-treatment to post-treatment changes for each variable were analysed. Paired t-tests was also used to evaluate the treatment difference between group 1 and group 2 .

\section{RESULTS}

The average times required for space closure were 11.82 months in G1 and 7.48 months in G2. All variables were differences obtained by subtraction of the T2 values from the T1 values. From (Figure 12) it can be seen that, a significant difference in retraction time was observed between control and corticotomy groups $(p<0.001)$. Implying that, the retraction time was significantly higher in control group as compared to corticotomy group. 


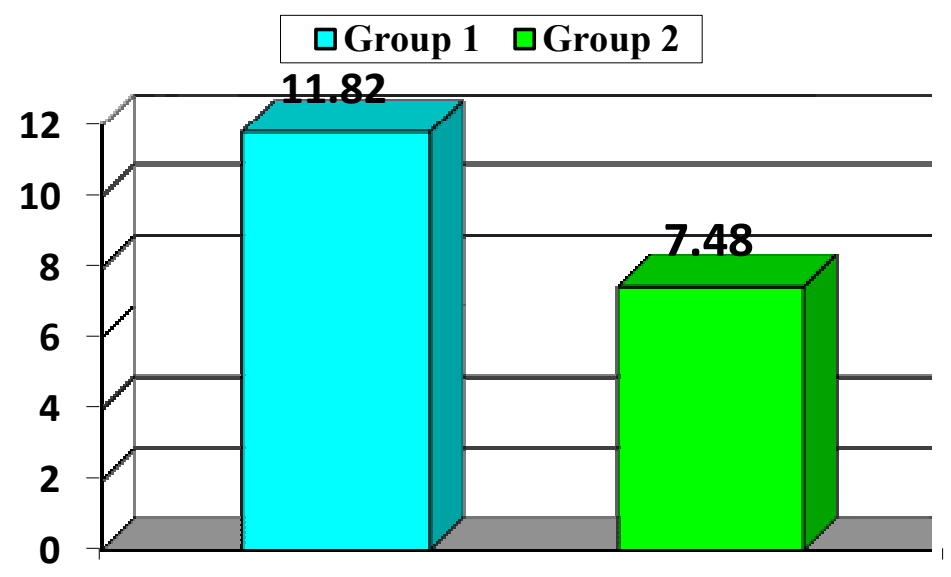

Mean duration of retraction (in months) in the two groups

There was a statistically significant difference in the SNA angle. Consequently, the ANB angle showed a statistically significant reduction (Table 1).

In maxillary incisor movement, statistically significant $(\mathrm{P} \leq 0.001)$ levels of retraction were achieved in the two groups for both angular and linear measurements within each group. While, there were no significant differences $(\mathrm{P} \geq 0.05)$ between the groups (Table 2$)$.

The amount of incisor retraction in the 2 groups was comparable with no statistical significance.

Table 1. Comparison of pretreatment and posttreatment skeletal changes (T2-T1) between groups

\begin{tabular}{|c|c|c|c|c|c|c|c|c|c|}
\hline \multirow{2}{*}{ Treatment } & \multirow{2}{*}{$\begin{array}{c}\text { Skeletal } \\
\text { Measurement }\end{array}$} & \multicolumn{2}{|c|}{ Before } & \multicolumn{2}{|c|}{ After } & \multirow{2}{*}{$\begin{array}{c}\text { Mean } \\
\text { Diff. }\end{array}$} & \multirow{2}{*}{$\begin{array}{l}\text { S.E. } \\
\text { Diff. }\end{array}$} & \multirow{2}{*}{ t value } & \multirow{2}{*}{$\mathbf{P}$} \\
\hline & & Mean & S.D. & Mean & S.D. & & & & \\
\hline \multirow{4}{*}{ Group 1} & SNA & 82.50 & 3.064 & 81.80 & 2.486 & -0.700 & 0.300 & -2.333 & $0.045 *$ \\
\hline & SNB & 74.90 & 2.998 & 74.70 & 2.869 & -0.200 & 0.249 & -0.802 & $0.443 \mathrm{NS}$ \\
\hline & ANB & 7.60 & 1.578 & 7.10 & 1.663 & -0.500 & 0.167 & -3.000 & $0.015 *$ \\
\hline & N-A-Pog & 16.20 & 3.615 & 13.80 & 4.022 & -2.400 & 1.067 & -2.250 & $0.050 *$ \\
\hline \multirow{4}{*}{ Group 2} & SNA & 84.40 & 3.064 & 82.70 & 2.486 & -1.700 & 0.300 & -5.667 & $0.001 * * *$ \\
\hline & SNB & 76.30 & 3.864 & 75.50 & 3.498 & -0.800 & 0.389 & -2.058 & $0.070 \mathrm{NS}$ \\
\hline & ANB & 8.10 & 3.302 & 7.20 & 3.028 & -0.900 & 0.314 & -2.862 & $0.019 *$ \\
\hline & N-A-Pog & 17.00 & 2.025 & 14.30 & 2.098 & -2.700 & 0.667 & -4.045 & $0.003 * *$ \\
\hline
\end{tabular}


Table 2. Comparison of pretreatment and posttreatment dental changes (T2-T1) between groups

\begin{tabular}{|c|c|c|c|c|c|c|c|c|c|}
\hline \multirow{2}{*}{ Treatment } & \multirow{2}{*}{$\begin{array}{c}\text { Dental } \\
\text { Measurement }\end{array}$} & \multicolumn{2}{|c|}{ Before } & \multicolumn{2}{|c|}{ After } & \multirow{2}{*}{$\begin{array}{c}\text { Mean } \\
\text { Diff. }\end{array}$} & \multirow{2}{*}{$\begin{array}{l}\text { S.E. } \\
\text { Diff. }\end{array}$} & \multirow{2}{*}{$t$ value } & \multirow{2}{*}{$\mathbf{P}$} \\
\hline & & Mean & S.D. & Mean & S.D. & & & & \\
\hline \multirow{5}{*}{ Group 1} & $\mathrm{U} 1-\mathrm{L} 1\left(^{\circ}\right)$ & 109.5 & 5.603 & 134.2 & 9.004 & 24.7 & 3.162 & 7.810 & $0.001 * * *$ \\
\hline & $\mathrm{U} 1-\mathrm{NA}\left({ }^{\circ}\right)$ & 25.2 & 5.712 & 9.0 & 4.028 & -16.2 & 2.026 & -7.994 & $0.001 * * *$ \\
\hline & $\mathrm{U} 1-\mathrm{FH}\left(^{\circ}\right)$ & 116.2 & 6.303 & 97.7 & 6.038 & -18.5 & 2.561 & -7.222 & $0.001 * * *$ \\
\hline & U1-NA (mm) & 7.3 & 2.406 & 0.8 & 0.919 & -6.5 & 0.687 & -9.459 & $0.001 * * *$ \\
\hline & U1-Apg (mm) & 14.7 & 2.791 & 5.8 & 1.033 & -8.9 & 0.809 & -11.002 & $0.001 * * *$ \\
\hline \multirow{5}{*}{ Group 2} & $\mathrm{U} 1-\mathrm{L} 1\left(^{\circ}\right)$ & 105.5 & 4.836 & 132.8 & 5.473 & 27.3 & 2.679 & 10.189 & $0.001 * * *$ \\
\hline & $\mathrm{U} 1-\mathrm{NA}\left({ }^{\circ}\right)$ & 24.4 & 9.058 & 8.6 & 4.789 & -15.8 & 2.394 & -6.601 & $0.001 * * *$ \\
\hline & $\mathrm{U} 1-\mathrm{FH}\left({ }^{\circ}\right)$ & 115.6 & 7.763 & 97.9 & 7.400 & -17.7 & 1.955 & -9.052 & $0.001 * * *$ \\
\hline & $\mathrm{U} 1-\mathrm{NA}(\mathrm{mm})$ & 7.8 & 2.201 & 1.7 & 1.160 & -6.1 & 0.605 & -10.089 & $0.001 * * *$ \\
\hline & $\mathrm{U} 1-\mathrm{Apg}(\mathrm{mm})$ & 16.1 & 2.514 & 7.3 & 1.889 & -8.8 & 0.646 & -13.615 & $0.001 * * *$ \\
\hline
\end{tabular}

S.D. $=$ Standard deviation.

$\mathrm{P}=$ Probability level for the effect of treatment (Paired t teats).

$\mathrm{NS}=$ Non significant $\mathrm{p}>0.05 \quad * \quad=$ Significant at $\mathrm{p} \leq 0.05$

$* *=$ Significant at $\mathrm{p} \leq 0.01 \quad * * *=$ Significant at $\mathrm{p} \leq 0.001$

\section{DISCUSSION}

Reduction of orthodontic therapy time is considered to be an important goal in the management of malocclusion. Corticotomy has been proposed as an alternative to conventional orthodontic treatment in difficult adult cases for rapid tooth movement.

Generally, the conventional corticotomy techniques include both labial and lingual corticotomy cuts like the procedures described by Generson et al ${ }^{15}$, Gantes et al ${ }^{16}$ and Wilcko et $\mathrm{al}^{2}$. In the current study the corticotomy cuts were performed on only the palatal side of the cortical bone. This technique is in agreement with Germec et al ${ }^{5}$ who reported rapid tooth movement when corticotomy was performed at the buccal aspects of alveolar bone and Nowzari et al ${ }^{6}$ who performed only buccal mucoperiosteal flaps, and selected vertical and horizontal 
Egyptian

Orthodontic Journal

corticotomy cuts were performed around the roots in both the maxillary and mandibular arches. Furthermore this agree with the study of Vercellotti and Podesta ${ }^{17}$ in which the corticotimes were performed on cortical bone in the direction of tooth movement as to retract the anterior teeth, only palatal corticotimes were performed.

The main purpose of this conservative, one stage surgery was to reduce the operation time and postoperative patient discomfort by eliminating exposure of the patient to the risks of labial and palatal surgery together. While even though palatal side less accessible, but the palatal cortical bone and width of the alveolar bone could be limiting factors in orthodontic retraction. Therefore palatal corticotomy may decrease the bone resistance to teeth movement toward palatal direction.

To obtain the desired tooth movement before the bone heals completely, it is necessary to apply orthodontic force immediately after the corticotomy, otherwise it loses effectiveness, and more frequent reactivation ( 2 weeks) is recommended according to wilcko 3,4 , Vercellotti and Podesta ${ }^{17}$ and Nowzari et al ${ }^{6}$. Therefore the en-massse retraction force was applied within one week after the surgery for corticotomized groups and were activated every two weeks. While, noncorticotomized group was activated every three weeks.

Although the average period for extraction space closure was significantly shorter in the corticotomy group than in the control group (7.48 months vs. 11.82 months, $p<0.05$ ), no significant difference in skeletal and dental relationships was observed between the two groups

\section{The duration of retraction}

The period of maxillary en-masse retraction in G2 (corticotomy group) was significantly less than in G1 (control group). This finding agrees with those of Wilcko et $\mathrm{al}^{4,}{ }^{18}$ Ino et al ${ }^{14}$ and Mostafa et al ${ }^{19}$ who reported that tooth movement combined with corticotomy was faster than that without corticotomy.

\section{Lateral cephalometric analysis:}

The treatment changes for each measurement were calculated by subtracting the pretreatment from the posttreatment measurements. In 
Egyptian

Orthodontic Journal

general, SNA Angle showed significant decrease between pre and post treatment within each group.

The decrease in SNA angle of G1 agree with Park et al ${ }^{11}$ who demonstrated that there was a significant decrease in SNA angle for the screw group. Regarding G2 the results were found to be compatible with the results of Choo et al ${ }^{20}$ and Tizini and Ibrahim ${ }^{21}$ in which a statistically significant decrease in SNA angle was recorded. In the current study, the angle of convexity (N-A-Pog) showed significant decrease for the effect of treatment (before -after) in G1and G2. This significant decrease is confirmed the significant decrease represented by SNA angle.

The studies of Kim et $\mathrm{al}^{22,}$ Upadhyay et $\mathrm{al}^{23}$ and Kim et $\mathrm{al}^{24}$ reported that statistically significant difference was found between the pretreatment and postretraction measurements in the anterior dentition which in accordance with the results of this study

The results of this study showed that en-masse retraction by using miniscrews as anchorage without corticotomy had no significant difference in treatment outcomes regarding the skeletal and dental measurements, when compared to that associated with corticotomy. This finding may be attributed to that the same treatment mechanics was applied for the two groups and the difference only was in performing of corticotomy in G2 which affect only the time taken for en-masse retraction.

\section{CONCLUSION}

The results of the study led to the following conclusions.

1) On comparing the retraction time of the two groups, it was found that there was a significant decrease in the treatment time in corticotomy group, when compared to the control group.

2) Although corticotomy procedure provides reduction in the period of en-masse retraction, but the treatment effects were comparable to that without corticotiony 
Egyptian

Orthodontic Journal

\section{REFERENCES}

1. Köle H. Surgical operations of the alveolar ridge to correct occlusal abnormalities. Oral Surg Oral Med Oral Pathol 1959; 12:515-29.

2. Wilcko WM, Wilcko T, Bouquot JE, Ferguson DJ. Rapid orthodontics with alveolar reshaping: two case reports of decrowding. Int J Periodontics Restorative Dent 2001; 21: 9-19.

3. Wilcko WM, Ferguson DJ, Bouquot JE, Wilcko MT. Rapid orthodontic decrowding with alveolar augmentation: Case Report. World J Orthod 2003; 4:197-205

4. Wilcko MT, Wilcko WM, Bissada NF. An evidence-based analysis of periodontally accelerated orthodontic and osteogenic techniques: a synthesis of scientific perspective. Semin Orthod. 2008; 14:305-316.

5. Germec D, Giray B, Kocadereli I, Enacar A. Lower incisor retraction with a modified corticotomy. Angle Orthod 2006; 76:882-890.

6. Nowzari H, Yorita FK, Chang HC. Periodontally accelerated osteogenic orthodontics combined with autogenous bone grafting. Compend. Contin Educ Dent.2008; 29 (4):200-206.

7. Aljhani AS, Aldrees AM. Orthodontic treatment of an anterior openbite with the aid of corticotomy procedure: Case report. Saudi Dent J 2011; 23:99-106.

8. Fischer T J. Orthodontic treatment acceleration with corticotomyassisted exposure of palatally impacted canines: a preliminary study. Angle Orthod. 2007; 77: 417-420.

9. Mostafa YA, EL-Mangoury NH, Abou-El-Ezz AM, Heider AM. Maximizing tissue response in selected subjects with anterior open bites. World J Orthod 2009; 10:187-195.

10. Lai EH, Yao CC, Chang JZ, Chen I, Chen YJ. Three dimensional dental model analysis of treatment outcomes for protrusive maxillary dentition: comparison of headgear, miniscrew, and miniplateskeletal anchorage. Am J Orthod Dentofacial Orthop. 2008; 134(5):636-645. 
Egyptian

Orthodontic Journal

11. Park HS, Yoon D Y, Park C S, Jeoung S H. Treatment effects and anchorage potential of sliding mechanics with titanium screws compared with the Tweed-Merrifield technique. Am J Orthod Dentofacial Orthop 2008; 133:593 600.

12. Upadhyay M, Yadav S, Nagaraj K, Patil S. Treatment effects of miniimplants for en-masse retraction of anterior teeth in bialveolar dental protrusion patients: A randomized controlled trial. Am J Orthod Dentofacial Orthop 2008; 134:18-29.

13. Yao CC, Lai EH, Chang JZ, Chen I, Chen YJ. Comparison of treatment outcomes between skeletal anchorage and extraoral anchorage in adults with maxillary dentoalveolar protrusion. Am J Orthod Dentofacial Orthop. 2008; 134:615-24.

14. Iino S, Sakoda S, Miyawaki S. An adult bimaxillary protrusion treated with corticotomy-facilitated orthodontics and titanium miniplates. Angle Orthod 2006; 76: 1074-1082.

15. Generson RM, Porter JM, Zell A, Stratigos GT. Combined surgical and orthodontic management of anterior open bite using corticotomy. J Oral Surg 1978; 34:216-219.

16. Gantes B, Rathbun E, Anholm M: Effects on the periodontium following corticotomy-facilitated orthodontics: case reports. J Periodontol. 1990; 61:234-238.

17. Vercellotti $\mathrm{T}$, and Podesta A. Orthodonctic microsurgery: a new surgically guided techniques for dental movement. Int J Periodontics Restorative Dent 2007; 27: 325-331.

18. Wilcko MT, Wilcko WM, Pulver JJ, Bissada NF, Bouquot JE. Accelerated Osteogenic Orthodontics Technique: A 1-Stage Surgically Facilitated Rapid Orthodontic Technique With Alveolar Augmentation. J Oral Maxillofac Surg 2009; 67:2149-2159

19. Mostafa YA, Fayed MMS, Mehanni S, El Bokle NN, and Heider AM Comparison of corticotomy-facilitated vs standard tooth-movement techniques in dogs with miniscrews as anchor units. Am J Orthod Dentofacial Orthop 2009; 136:570-577. 
20. Choo HR., Heo HA, Yoon HJ, Chung KR, Kim SH. Treatment outcome analysis of speedy surgical orthodontics for adults with maxillary protrusion. Am J Orthod Dentofacial Orthop 2011; 140:251-262.

21. Tizini $M$ and Ibrahim G. Retraction of the upper maxillary incisors with corticotomy-facilitated orthodontics and mini-implants. Saudi J Dent Res 2013; 1-6.

22. Kim SH, Hwang YS, Ferreira A, Chung KR. Analysis of temporary skeletal anchorage devices used for en-masse retraction: A preliminary study. Am J Orthod Dentofacial Orthop 2009; 136:268-276.

23. Upadhyay M, Yadav S, Nagaraj K, Nanda R. Dentoskeletal and soft tissue effects of mini-implants in class II division 1 patients. Angle Orthod. 2009; 79(2):240-247.

24. Kim JS, Kim SH, Kook YA, Chung KR, Nelson G. Analysis of lingual en masse retraction combining a $\mathrm{C}$-lingual retractor and a palatal plate. Angle Orthod 2011; 81: 662-669. 